\title{
Características estruturais e físico-químicas de amidos de mandioquinha-salsa (Arracacia xanthorrhiza)
}

\author{
Structural and physicochemical characteristics of Peruvian carrot (Arracacia xanthorrhiza) starch
}

Thaís Souza ROCHA ${ }^{1}$, Ivo Mottin DEMIATE², Célia Maria Landi FRANCO ${ }^{1 \star}$

\begin{abstract}
Resumo
O amido apresenta propriedades físico-químicas importantes que são dependentes de sua fonte botânica e de suas características estruturais. $\mathrm{O}$ amido de mandioquinha-salsa possui características especiais que o tornam elegível para utilização em vários alimentos processados. Neste trabalho, amidos de duas variedades de mandioquinha-salsa, Amarela de Carandaí (AC) e Amarela de Senador Amaral (ASA), foram isolados e suas características físico-químicas e estruturais determinadas. O amido obtido da variedade ASA apresentou grânulos com diâmetro médio maior que aqueles da variedade $\mathrm{AC}$ e mais que o dobro da quantidade de grânulos com tamanho $\geq 20 \mu \mathrm{m}$, quando comparado à outra variedade. Os amidos de ambas as variedades, observados em microscópio eletrônico de varredura, mostraram superfícies granulares lisas com formatos circulares e poliédricos para grânulos grandes e pequenos, respectivamente. A distribuição de tamanho molecular, viscosidade intrínseca e índice de cristalinidade dos amidos de ambas as variedades foram semelhantes, porém o teor de amilose foi maior para o amido da variedade AC. Maiores valores de viscosidade, poder de inchamento, e temperaturas de gelatinização foram observados para o amido da variedade ASA e podem estar relacionados ao menor teor de amilose e à maior proporção de grânulos grandes apresentados por este amido.
\end{abstract}

Palavras-chave: amido; mandioquinha-salsa; estrutura; propriedades físico-químicas.

\begin{abstract}
Starch has very important physicochemical properties that depend on its botanical source and structural characteristics. Peruvian carrot starch displays special characteristics, which make it appropriate for industrial application in many processed foods. In this work, starch from two Peruvian carrot varieties, Amarela de Carandaí (AC) and Amarela de Senador Amaral (ASA), were isolated and their physicochemical and structural properties were determined. Starch from the ASA variety exhibited granules with a greater average diameter than those from the $\mathrm{AC}$ variety and more than double the number of granules with size $\geq 20 \mu \mathrm{m}$, when compared to the other variety. Starches from both varieties, observed in a Scanning Electron Microscope, showed smooth granule surface with circular and polyhedral shapes for large and small granules, respectively. Molecular size distribution, intrinsic viscosity and degree of cristallinity of starches from both varieties were similar; however, amylose content was higher for the starch from the AC variety. Higher values of viscosity, swelling power and gelatinization temperatures were observed for the starch from the ASA variety, which could be related to the lower amylose content and the higher proportion of large granules exhibited by this starch.

Keywords: starch; Peruvian carrot; structural characteristics; physicochemical properties.
\end{abstract}

\section{Introdução}

O amido é um carboidrato encontrado em abundância na natureza, só competindo em quantidade com a celulose. Apresenta-se na forma de grânulos com formato e tamanho dependentes da sua fonte botânica. Devido as suas propriedades físico-químicas e funcionais exclusivas, este carboidrato tem grande importância nos mais diversos setores industriais. $\mathrm{Na}$ indústria de alimentos nacional e na internacional o amido é utilizado como ingrediente, podendo, entre outras funções, facilitar o processamento, fornecer textura, servir como espessante, fornecer sólidos em suspensão ou proteger os alimentos durante o processamento. Pode ser utilizado na sua forma natural ou, por intermédio de processamentos adicionais, dar origem a produtos como amidos modificados, xaropes de glicose, maltose ou frutose e maltodextrinas, entre outros (FRANCO et al., 2001).
Os grânulos de amido são misturas heterogêneas de duas macromoléculas, amilose e amilopectina, que diferem no tamanho molecular e grau de ramificação (MIZUKAMI; TAKEDA; HIZUKURI, 1999). A amilose é uma molécula essencialmente linear formada por unidades de glicose ligadas em $\alpha-1,4$, apresentando pequeno número de ramificações (BULÉON et al., 1998), enquanto a amilopectina é uma molécula altamente ramificada, também composta de unidades de glicose ligadas em $\alpha-1,4$, mas com 5 a $6 \%$ de ligações $\alpha-1,6$ nos pontos de ramificação (FRENCH, 1984; LINEBACK, 1984).

A compreensão da estrutura dos grânulos de amido é importante no entendimento de suas propriedades físico-químicas, as quais determinam o comportamento do amido natural ou

Recebido para publicação em 4/4/2007

Aceito para publicação em 19/10/2007 (002427)

${ }^{1}$ Departamento de Engenharia e Tecnologia de Alimentos, Instituto de Biociências Letras e Ciências Exatas, Universidade Estadual Paulista - UNESP,

Rua Cristóvão Colombo, 2265, Jd. Nazareth, CEP 15054-000, São José do Rio Preto - SP, Brasil

2 Setor de Ciências Agrárias e de Tecnologia, Departamento de Engenharia de Alimentos, Universidade Estadual de Ponta Grossa - UEPG, Av. General Carlos Cavalcanti, 4748, Uvaranas, CEP 84030-900, Ponta Grossa - PR, Brasil

${ }^{*}$ A quem a correspondência deve ser enviada 
modificado, nos mais diversos processos industriais a que eles normalmente são submetidos (BEMILLER, 1997).

As propriedades de gelatinização do amido estão relacionadas a vários fatores, incluindo proporção de amilose e amilopectina, tipo de cristalinidade, tamanho e estrutura do grânulo de amido (LINDEBOOM; CHANG; TYLER, 2004). A amilopectina contribui para o inchamento do grânulo, enquanto a amilose e os lipídios o inibem (TESTER; MORRISON, 1990).

Os grânulos de amido estão organizados em regiões cristalinas e amorfas, sendo a transição entre elas gradual. A região cristalina é constituída de cadeias laterais da amilopectina, enquanto que os pontos de ramificação e a amilose são os principais componentes das regiões amorfas (PARKER; RING, 2001). Desse modo, a cristalinidade dos grânulos, normalmente determinada por difractometria de Raio x, é descrita principalmente em função das duplas hélices formadas pelas ramificações da amilopectina (HOOVER, 2001). As áreas cristalinas do amido mantêm a estrutura do grânulo, controlam o seu comportamento na água, tornando-o relativamente resistente ao ataque enzimático e químico (FRANCO et al., 2001). Esta estrutura cristalina depende do tipo e grau de associação intermolecular existente entre os componentes do amido (SINGH et al., 2003).

A interação entre os componentes das regiões cristalinas e amorfas é influenciada pela razão entre amilose e amilopectina, e pelas características desses polímeros em termos de peso e distribuição molecular e grau e tamanho das ramificações (HOOVER, 2001).

As fontes de amido mais utilizadas mundialmente são, em grande parte, as de cereais como milho e trigo, e as de raízes e tubérculos, como mandioca, batata e batata-doce. Pesquisas para utilização de outras raízes e tubérculos, como fontes de amido, são recentes principalmente porque essas matérias-primas se desenvolvem melhor em climas tropicais, onde está localizada a maioria dos países em desenvolvimento (FRANCO et al., 2001).

A mandioquinha-salsa é originária da região andina da América do Sul compreendida por Venezuela, Equador, Peru, Bolívia e, sobretudo, pela Colômbia. No Brasil, atualmente o maior produtor desta raiz, a mandioquinha-salsa foi introduzida por volta de 1900, trazida das Antilhas (CASALI; SEDYAMA, 1997), sendo cultivada e consumida nas regiões Sudeste e Sul do país. A variedade mais utilizada no Brasil é conhecida como Amarela de Carandaí ou Amarela Comum. Outra, a variedade Amarela de Senador Amaral é uma cultivar obtida pela seleção de mudas originárias da variedade comum e produzida no sul de Minas Gerais (BUENO, 2004).

Em relação ao valor alimentício, as raízes tuberosas da mandioquinha-salsa, comumente consumidas, constituem um alimento de bom valor nutritivo se comparadas às de outras espécies amiláceas como mandioca, batata, cará e batata-doce. Caracteriza-se como um alimento essencialmente energético, apresentando $25 \mathrm{~g}$ de carboidratos, em média, por $100 \mathrm{~g}$ de raiz. Embora se constitua como boa fonte de vitamina A e niacina, apresenta também consideráveis níveis de minerais, como cálcio, fósforo e ferro, podendo ser caracterizada como um alimento nutracêutico, recomendado em dietas para crianças, pessoas idosas e convalescentes (PEREIRA, 1995). Dos carboidratos totais, a maior fração corresponde ao amido, que representa cerca de 80\% (BUENO, 2004).

O amido de mandioquinha-salsa é considerado de fácil cozimento. Ele apresenta baixa temperatura de gelatinização e alta viscosidade de pico, sendo suscetível ao atrito mecânico. Também possui baixa tendência à retrogradação e sinérese, o que contribui para sua alta digestibilidade (PERONI, 2003). Por este amido apresentar propriedades funcionais especiais, esta raiz pode ser utilizada com sucesso no preparo de sopas, papinhas, pães, purês, nhoques e bolos.

Neste trabalho, amidos isolados das duas variedades de mandioquinha-salsa foram analisados e suas características estruturais e físico-químicas correlacionadas.

\section{Material e métodos}

Raízes de mandioquinha-salsa (Arracacia xanthorrhiza), das variedades Amarela de Carandaí (AC) e Amarela de Senador Amaral (ASA), oriundas de Piraí do Sul na região de Ponta Grossa-PR, e colhidas após tempo de plantio de 11 e 9 meses, respectivamente, foram utilizadas neste trabalho. As enzimas puras $\alpha$-amilase bacteriana (A6380) e amiloglucosidase fúngica (A7420) foram obtidas da Sigma Chemical CO., EUA. Todos os reagentes utilizados foram puros para análise.

\subsection{Isolamento dos amidos}

As raízes de mandioquinha-salsa foram lavadas e descascadas, cortadas em cubos e trituradas com água destilada a $5^{\circ} \mathrm{C}$, na proporção de 1:1 (v/v), em liquidificador industrial durante 1 minuto. O material moído foi passado através de peneiras de 80 mesh $(0,177 \mathrm{~mm})$ para separação das fibras, e em peneira de 150 mesh $(0,105 \mathrm{~mm})$, em seguida foi mantido em repouso por aproximadamente 12 horas a $5^{\circ} \mathrm{C}$, para decantação do amido. Após este tempo, o sobrenadante foi drenado por sifonação. $\mathrm{O}$ amido foi ressuspendido em água e recuperado por centrifugação a 1700 g por 15 minutos, lavado com água e etanol e seco em estufa com circulação forçada de ar a $38^{\circ} \mathrm{C}$.

\subsection{Composição centesimal}

Os teores de umidade, lipídios, proteínas, cinzas e fibras foram determinados pelos métodos descritos em Approved Methods of the American Association of Cereal Chemists (AACC, 1995). O teor de fósforo foi determinado de acordo com o método espectrofotométrico de Smith e Caruso (1964). $\mathrm{O}$ teor de carboidratos foi determinado por diferença entre o total de matéria seca.

\subsection{Distribuição de tamanho dos grânulos}

A distribuição de tamanho dos grânulos de amido de mandioquinha-salsa, de ambas as variedades, foi determinada através de microscópio óptico de luz (marca Olympus), acoplado a um sistema de análise de imagem Image-Pro-Plus (Media Cybernetics). Três lâminas para cada amostra foram preparadas com duas gotas de suspensão de $0,1 \mathrm{~g}$ de amido em $5 \mathrm{~mL}$ de solução 1:1 de glicerina/água. De cada lâmina foram 
tomadas medidas de 300 grânulos. O tamanho foi determinado a partir da medição do diâmetro maior dos grânulos.

\subsection{Microscopia eletrônica de varredura}

Imagens dos grânulos de amido foram obtidas por microscopia eletrônica de varredura, com aumentos de 500 e 3000x, realizadas em microscópio eletrônico de varredura, modelo DSM 960 ZEISS - Digital Scanning Microscope. Uma pequena quantidade de amostra foi colocada sobre fita adesiva de carbono, aderida a um disco metálico e este levado a um metalizador Balzers, modelo SCD 050, para aplicação de uma camada de ouro com $20 \mathrm{~nm}$ de espessura. As amostras assim preparadas foram observadas em microscópio.

\subsection{Distribuição do tamanho molecular dos componentes do amido por cromatografia de permeação em gel}

Amostras dos amidos foram preparadas seguindo o procedimento descrito por Song e Jane (2000). Uma alíquota $(5,0 \mathrm{~mL}$ ) contendo $15 \mathrm{mg}$ de amido e $0,5 \mathrm{mg}$ de glicose (como marcador) foi aplicada à base da coluna $(1,0 \times 70,0 \mathrm{~cm})$ empacotada com gel Sepharose CL-2B, segundo os procedimentos de Wang et al. (1993). A coluna foi eluída de modo ascendente. O eluente utilizado foi $\mathrm{NaCl} / \mathrm{NaOH}(25 \mathrm{mM} / 1 \mathrm{mM})$, com fluxo de $0,5 \mathrm{~mL} /$ minuto. Frações de 2,5 $\mathrm{mL}$ foram coletadas e analisadas quanto ao teor de açúcares totais, usando-se metodologia fenol sulfúrico (DUBOIS et al., 1956), modificada para leitura em microleitora de absorbância segundo procedimento descrito por Fox e Robyt (1991), e também foram analisadas através de reação de coloração com iodo, pelo método de blue value (JULIANO, 1971), para revelar a distribuição de tamanho molecular da amilose e amilopectina.

\subsection{Teor de amilose}

Amostras dos amidos foram previamente desengorduradas conforme descrito por Franco et al. (2002). A determinação do teor de amilose dos amidos desengordurados foi realizada seguindo a metodologia ISO (1987). O teor de amilose foi calculado a partir de curvas padrão de amilose e amilopectina.

\subsection{Difração de Raio $x$}

Os padrões de difração de Raio $\mathrm{x}$ dos amidos foram determinados, utilizando-se uma unidade RINT 2000 (Wide Angle Goniometer) com radiação de $\mathrm{Cu}$, linha $\mathrm{K}, \mathrm{L}=1,542 \mathrm{~A}$. A velocidade de varredura foi de $1^{\circ}$ por minuto e as condições de uso foram de $50 \mathrm{kV}$ e $100 \mathrm{~mA}$. O Índice de Cristalinidade relativa (IC) foi quantitativamente estimado como proposto por Hayakawa et al. (1997) e mostrado na Figura 1. O IC foi definido como a razão entre a área da região cristalina e a área total coberta pela curva, composta pela área da região cristalina e a área da região amorfa, conforme a Equação 1:

$I C(\%)=\frac{A_{c}}{A_{c}+A_{a}} \times 100$

em que $A_{c}=$ área cristalina; $A_{a}=$ área amorfa no difractograma.

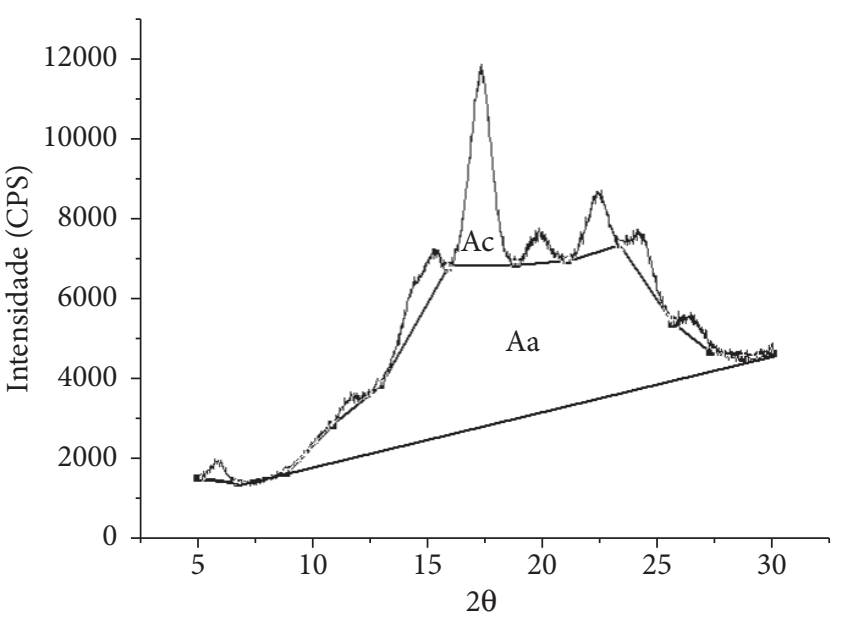

Figura 1. Difractograma de Raio x descritivo do método de índice de cristalinidade relativa adaptado à razão das intensidades difratadas.

\subsection{Susceptibilidade enzimática}

Os amidos granulares foram hidrolisados $\operatorname{com} \alpha$-amilase bacteriana e amiloglucosidase fúngica seguindo metodologia de Franco e Ciacco (1992). Dispersões de amido (10\% p/v) em solução tampão fosfato $0,5 \mathrm{M} \mathrm{pH} 5,5$ contendo $60 \mathrm{SKB} / \mathrm{g}$ de amido de $\alpha$-amilase e 1,5 unidades de atividade/g de amido de amiloglucosidase fúngica foram incubadas a $37^{\circ} \mathrm{C}$ durante 48 horas. A extensão da hidrólise foi determinada pela quantidade de açúcares redutores presentes no sobrenadante, quantificados segundo metodologia de Somogyi (1945).

\subsection{Viscosidade intrínseca}

Soluções de amido foram preparadas segundo Lansky, Kooi e Schoch (1949) e analisadas quanto à viscosidade intrínseca de acordo com Leach (1963). Para determinar o tempo de escoamento do solvente $(\mathrm{KOH} 1 \mathrm{~N})$ e das soluções de amido, exatos $12 \mathrm{~mL}$ foram transferidos para um viscosímetro Cannon Fenske $\mathrm{n}^{\circ} 50$, mantido em banho termostatizado a $35^{\circ} \mathrm{C}$. A viscosidade específica foi calculada utilizando-se a Equação 2:

$\eta_{s p}=\left(\frac{\eta}{\eta_{0}}-1\right)=\left(\frac{t}{t_{0}}-1\right)$

em que $\eta_{s p}=$ viscosidade específica; $\eta=$ viscosidade da solução de amido; $\eta_{0}=$ viscosidade do solvente $\mathrm{KOH} 1 \mathrm{~N} ; t=$ tempo de escoamento da solução de amido; e $t_{0}=$ tempo de escoamento do solvente.

A determinação da viscosidade intrínseca foi baseada na extrapolação, à concentração zero, da reta obtida por ajuste matemático dos pontos experimentais da curva de viscosidade específica em função da concentração da solução.

\subsection{Propriedades de pasta e propriedades térmicas}

As propriedades de pasta e térmicas dos amidos foram determinadas usando-se um Rápido Visco Analisador RVA-4 
(Newport Scientific, Austrália) e um Calorímetro Diferencial de Varredura Pyris 1 - (Perkin Elmer, USA), respectivamente, de acordo com Franco et al. (2002).

\subsection{Poder de inchamento}

O poder de inchamento dos amidos foi determinado de acordo com Schoch (1964) com modificações. Suspensões de $0,2 \mathrm{~g}$ (b.s.) de amido em $18 \mathrm{~g}$ de água destilada foram colocadas em tubos com tampa, que foram mantidos em banho de água com agitação a $60,70,80$ ou $90^{\circ} \mathrm{C}$ por 30 minutos. Após este tempo, os tubos foram retirados do banho, secos e pesados. O peso da mistura foi completado para exatamente $20 \mathrm{~g}$ com água destilada. Os tubos foram fechados, invertidos para homogeneização e centrifugados a $2090 \mathrm{~g}$ por 15 minutos. O sobrenadante foi removido cuidadosamente e o poder de inchamento determinado como o peso do sedimento dividido pelo peso de amido seco (g.g $\left.{ }^{-1}\right)$.

\subsection{Análise estatística}

O delineamento experimental adotado para os experimentos foi o inteiramente casualizado, sendo os tratamentos compostos por duas a três repetições. Os dados foram avaliados pelo emprego do programa ESTAT - Sistema para Análises Estatísticas, versão 2.0, abrangendo a análise de comparação de médias pelo teste de Tukey $(\mathrm{p}<0,05)$.

\section{Resultados e discussão}

\subsection{Composição centesimal}

A composição química dos amidos obtidos das duas variedades de mandioquinha-salsa encontra-se dentro dos limites apresentados na literatura para este amido (PERONI, 2003; VIEIRA, 2004). Como esperado para amidos de raízes e tubérculos, os amidos de mandioquinha-salsa mostraram baixos teores de proteínas e lipídios. Os teores de cinzas, proteínas, lipídios e fibras somados não atingiram $1 \%$ do total, indicando que os amidos apresentaram alto grau de pureza e que o processo de extração, em laboratório, foi eficiente (Tabela 1).

O fósforo presente em amidos, dependendo de sua forma, causa diferentes efeitos nas propriedades funcionais. No caso de amidos de cereais, esse mineral geralmente está presente na forma de fosfolipídios (TESTER; MORRISON, 1990; BLENNOW; ENGELSEN; MUNCK, 2000), enquanto que em amidos de raízes e tubérculos, principalmente na forma de monoéster

Tabela 1. Composição química dos amidos de mandioquinha-salsa ${ }^{1}$.

\begin{tabular}{lcc}
\hline & AC $\left(\mathrm{g} \cdot 100 \mathrm{~g}^{-1}\right)$ & ASA $\left(\mathrm{g} \cdot 100 \mathrm{~g}^{-1}\right)$ \\
\hline Carboidratos totais & $99,63 \pm 0,18$ & $99,71 \pm 0,21$ \\
Fibras & $0,26 \pm 0,08$ & $0,21 \pm 0,11$ \\
Lipídios & $0,13 \pm 0,03$ & $0,10 \pm 0,02$ \\
Proteínas & $0,12 \pm 0,01$ & $0,10 \pm 0,01$ \\
Cinzas & $0,12 \pm 0,01$ & $0,09 \pm 0,01$ \\
Fósforo & $0,018 \pm 0,001$ & $0,017 \pm 0,001$ \\
\hline
\end{tabular}

${ }^{1}$ Resultados expressos em base seca; cada valor representa a média \pm desvio padrão de duas determinações; $e^{*}$ determinado por diferença. fosfato, ligado covalentemente às moléculas de amilopectina (KASEMSUWAM; JANE, 1994). Amidos de raízes e tubérculos geralmente apresentam valores elevados deste mineral, como é o caso do amido de batata que possui $0,089 \%$ (LIM; KASEMSUWAM; JANE, 1994) e o amido de biri $(0,031 \%)$ (PERONI; ROCHA; FRANCO, 2006). Ambas as variedades de mandioquinha-salsa mostraram valores semelhantes de fósforo no amido ( $0,017 \%)$, concordando com resultados obtidos anteriormente por Peroni (2003).

\subsection{Distribuição do tamanho dos grânulos}

$\mathrm{O}$ amido da variedade ASA apresentou diâmetro médio de $14,7 \mu \mathrm{m}$, valor maior do que o mostrado pela variedade AC $(11,0 \mu \mathrm{m})$ (Tabela 2). Bermudez (1997) e Vieira (2004) encontraram, para duas amostras de amido de mandioquinha-salsa, diâmetro médio de $10 \mu \mathrm{m}$ e de $17,3 \mu \mathrm{m}$, respectivamente, sem especificar a variedade da raiz estudada para cada uma delas. As diferenças no tamanho médio dos grânulos, encontradas por diferentes autores, podem ser devido ao uso de plantas de diferentes variedades, idades ou épocas de colheita, ou ainda podem decorrer de diferentes metodologias de mensuração do tamanho.

Analisando a distribuição de tamanho dos grânulos (Figura 2), pode-se notar que o amido da variedade ASA apresentou menor quantidade de grânulos com diâmetro menor que $10 \mu \mathrm{m}(35 \%)$ e mais que o dobro do número de grânulos com diâmetro acima de $20 \mu \mathrm{m}(22,8 \%)$ quando comparado com a variedade $\mathrm{AC}$, que apresentou $51,1 \%$ de grânulos pequenos e 8,5\% de grânulos grandes. Essa diferença na distribuição de tamanho dos grânulos poderia estar relacionada com a precocidade no desenvolvimento da variedade ASA (BUENO, 2004), porém não foi encontrado, até o momento, qualquer estudo ou evidência que suporte essa idéia.

\subsection{Microscopia eletrônica de varredura}

Os grânulos de amido de mandioquinha-salsa, quando observados em microscópio eletrônico de varredura (Figura 3), apresentaram superfícies lisas com alguns grânulos, principalmente os de maior diâmetro, apresentando orifícios ou fendas na sua superfície (evidenciados pelas setas na Figura 3), que parecem ser característicos destes amidos. Estes orifícios ou fendas apresentados por estes grânulos poderiam influenciar algumas características físico-químicas dos amidos, entre elas, a suscetibilidade enzimática, uma vez que facilitaria a penetração das enzimas no interior dos grânulos (WANG; POWELL; OATES, 1995). Os grânulos grandes de ambas as variedades mostraram formas predominantemente circulares, enquanto os pequenos mostraram formatos mais poliédricos ou poligonais.

Tabela 2. Diâmetro médio, teor de amilose, índice de cristalinidade e viscosidade intrínseca dos grânulos de amido de mandioquinha-salsa ${ }^{a}$.

\begin{tabular}{ccccc}
\hline Amido & $\begin{array}{c}\text { Diâmetro } \\
\text { médio }^{*}\end{array}$ & $\begin{array}{c}\text { Teor de } \\
\text { amilose }\end{array}$ & IC & $\begin{array}{c}\text { Viscosidade } \\
\text { intrínseca }\end{array}$ \\
\hline AC & $11,0 \mu \mathrm{m}^{\mathrm{b}}$ & $21,67 \%^{\mathrm{a}}$ & $21,4 \%^{\mathrm{a}}$ & $2,39^{\mathrm{a}}$ \\
ASA & $14,7 \mu \mathrm{m}^{\mathrm{a}}$ & $17,81 \%^{\mathrm{b}}$ & $19,7 \%^{\mathrm{a}}$ & $2,18^{\mathrm{a}}$ \\
\hline
\end{tabular}

${ }^{*}$ Considerando o diâmetro maior de cada grânulo; $\mathrm{e}^{\mathrm{a}}$ valores seguidos pela mesma letra na mesma coluna não diferem significativamente pelo teste de Tukey $(\mathrm{p}<0,05)$. 


\subsection{Distribuição do tamanho molecular dos componentes dos amidos por cromatografia de permeação em gel}

Os perfis de eluição dos amidos (Figura 4) apresentaram um primeiro pico correspondente à amilopectina, com grande massa molecular, que foi eluída no volume vazio da coluna. $\mathrm{O}$

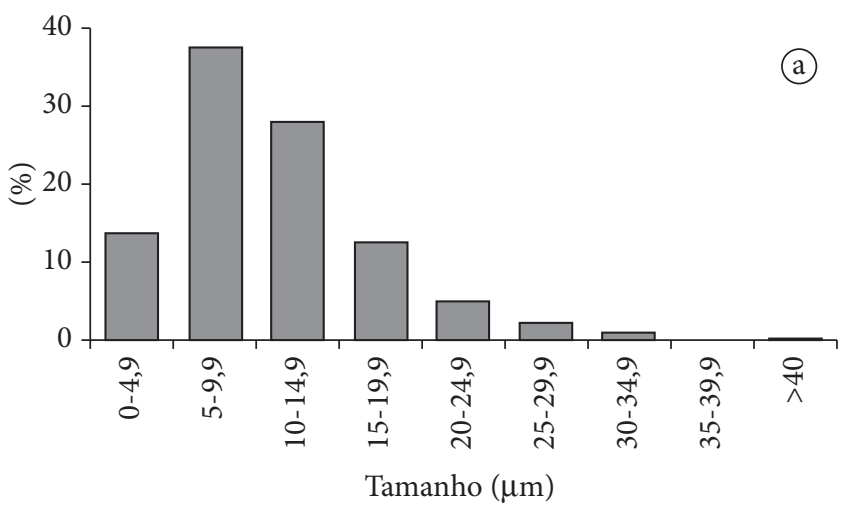

segundo pico, com alta resposta de Blue Value (BV), correspondeu à amilose, e o último pico correspondeu à glicose adicionada à amostra para marcar o final da eluição.

Os cromatrogramas obtidos para os amidos das duas variedades apresentaram-se semelhantes, com os picos de

Figura 2. Distribuição do tamanho dos grânulos de amido de mandioquinha-salsa: a) AC; e b) ASA.
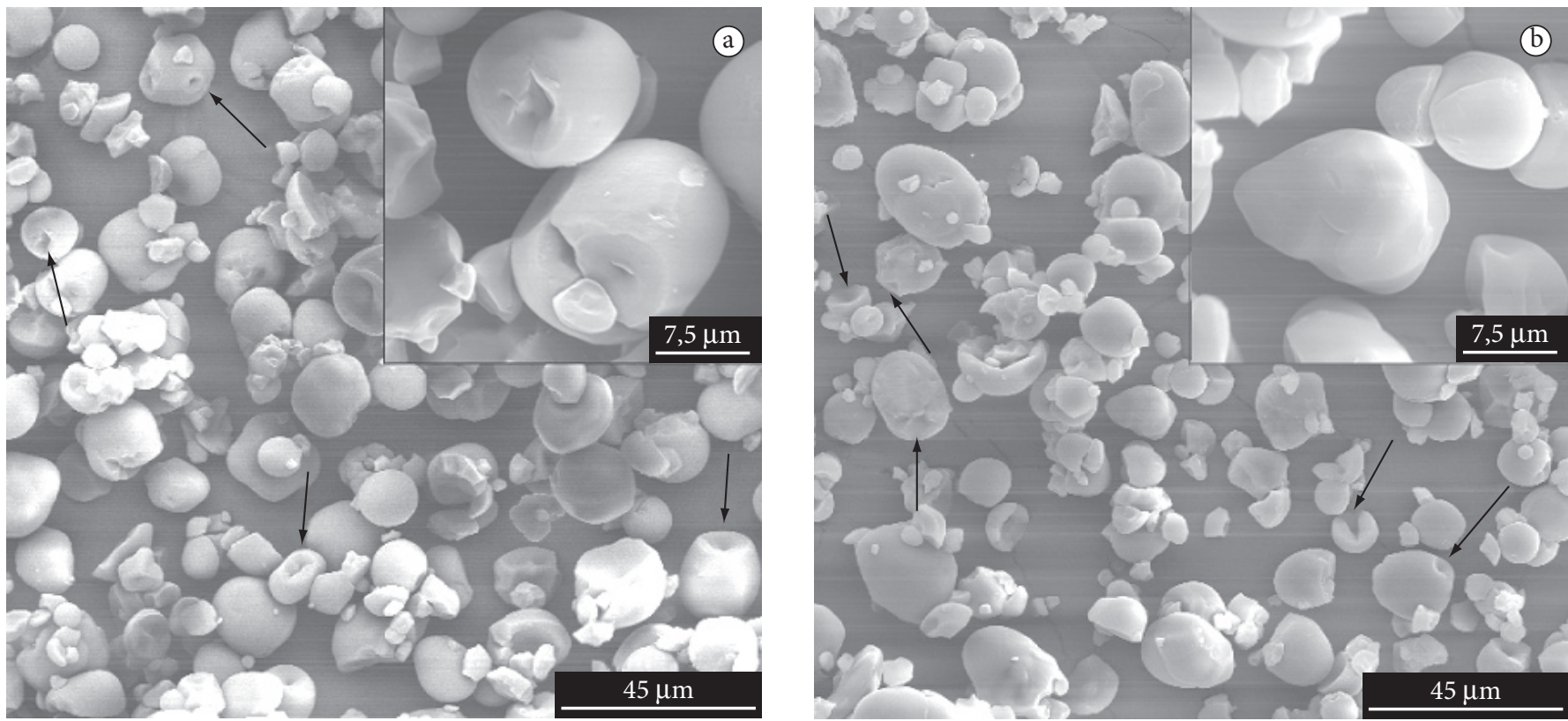

Figura 3. Micrografias dos grânulos de amido de mandioquinha-salsa observados em microscópio eletrônico de varredura: a) AC; e b) ASA (aumento: 500x; 3000x no destaque).

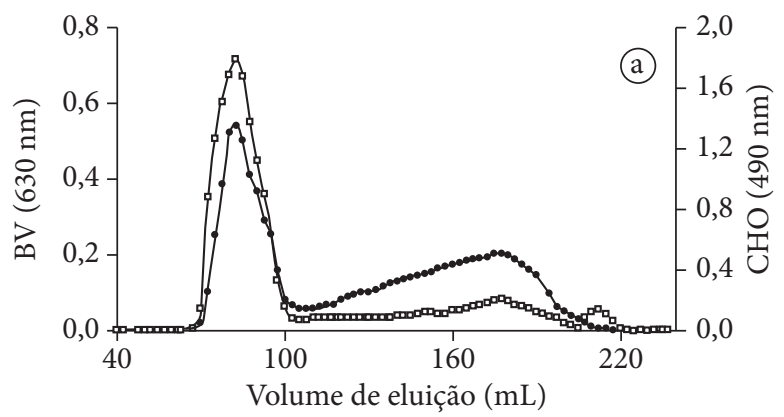

$$
\rightarrow \mathrm{BV} \rightarrow \mathrm{CHO}
$$

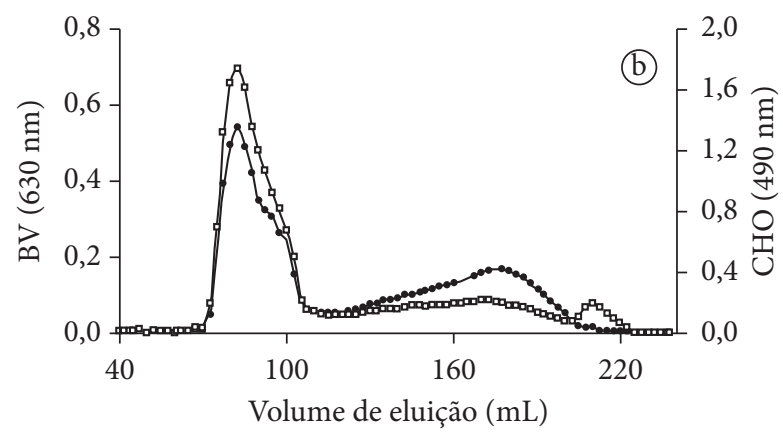

Figura 4. Perfil de eluição dos amidos de mandioquinha-salsa em Sepharose CL-2B: a) AC; e b) ASA. 
amilopectina e amilose eluídos nos volumes de 82,5 e $175 \mathrm{~mL}$, respectivamente, sugerindo que ambos os amidos apresentaram amiloses com massas moleculares semelhantes.

A razão de blue value e açúcar total (BV/CHO) no pico da amilopectina foi semelhante para ambos os amidos, com valor próximo a 0,30 , um valor baixo quando comparado com valores encontrados para amidos de outras fontes botânicas como mandioca $(0,38)$, araruta $(0,45)$, batata-doce $(0,51)$ e inhame $(0,68)$ (PERONI; ROCHA; FRANCO, 2006). Esses resultados sugerem menores proporções de cadeias laterais longas da amilopectina para o amido de mandioquinha-salsa quando comparado a outras fontes botânicas.

A maior resposta de BV no pico da amilose para o amido da variedade $\mathrm{AC}$ indicou maior teor de amilose para este amido quando comparado ao obtido da variedade ASA.

\subsection{Teor de amilose}

Os teores de amilose estão apresentados na Tabela 2. O amido da variedade AC mostrou maior teor de amilose do que o amido da outra variedade, confirmando os resultados observados na distribuição do tamanho molecular dos amidos apresentados na Figura 4.

A porcentagem de amilose encontrada para o amido da variedade AC $(21,67 \%)$ mostrou-se semelhante àquela observada por Peroni (2003) e por Gonzáles e Carrasco (2001), que encontraram valores de 21,3 e $20 \%$, respectivamente, para o amido de mandioquinha-salsa. Já o teor de amilose observado para o amido da variedade ASA $(17,81 \%)$ ficou próximo ao valor encontrado por Vieira (2004) (17,2\%). Estes autores não relataram a variedade de mandioquinha-salsa estudada. Desta forma, com base nos resultados obtidos neste trabalho, as diferenças nos teores de amilose encontradas na literatura podem ser devido à utilização de variedades diferentes.

\subsection{Difração de Raio $x$}

Os amidos das duas variedades de mandioquinha-salsa apresentaram difractogramas muito semelhantes (Figura 5), com os picos principais exibidos a 5,$7 ; 15 ; 17,2 ; 19,8 ; 22,6$ e $24,4^{\circ} \mathrm{em} 2 \theta$, mostrando padrão de difração do tipo B. A maioria dos amidos de raízes e tuberosas possui padrão de difração de Raio x do tipo B. Algumas exceções são os amidos de batata-doce (Ipomoea batatas) (A, C), de mandioca (Manihot esculenta) $\left(\mathrm{A}, \mathrm{C}, \mathrm{C}_{\mathrm{a}}\right) \mathrm{e}$ inhame (Discorea dumetorum) (A) (HOOVER, 2001).

$\mathrm{O}$ grau de cristalinidade de amidos nativos varia de 15 a 45\% (CHEETHAM; TAO, 1998). Apesar do teor de amilose do amido da variedade AC ser significativamente maior do que o do amido da variedade ASA, os Índices de Cristalinidade (IC) de ambos os amidos não apresentaram diferenças e giraram em torno de 20\% (Tabela 2).

\subsection{Susceptibilidade enzimática}

A quantidade de açúcar redutor produzida durante a hidrólise enzimática para os amidos de mandioquinha-salsa mostrou que o perfil de hidrólise foi semelhante para as duas variedades analisadas (Figura 6). A velocidade de hidrólise foi

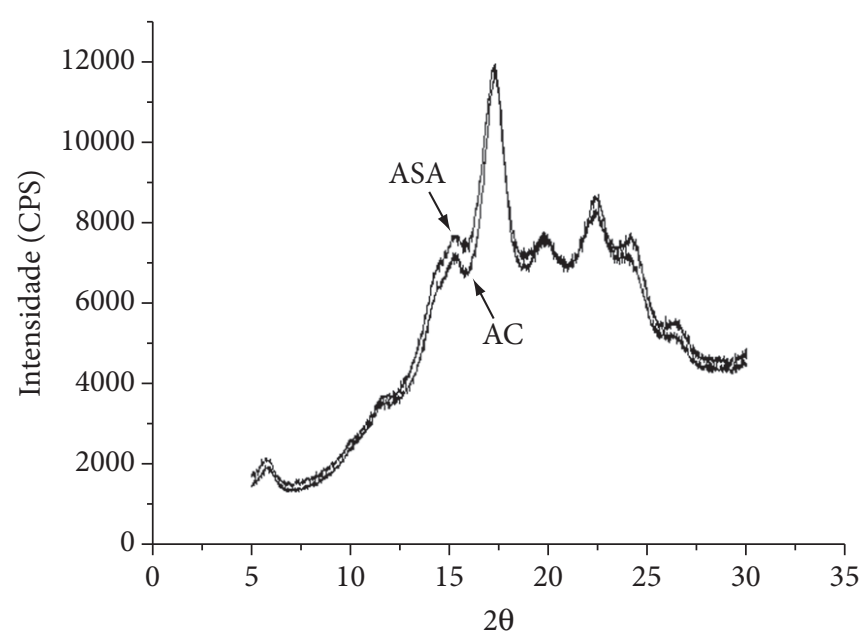

Figura 5. Difractogramas de Raio $\mathrm{x}$ dos amidos de mandioquinhasalsa.

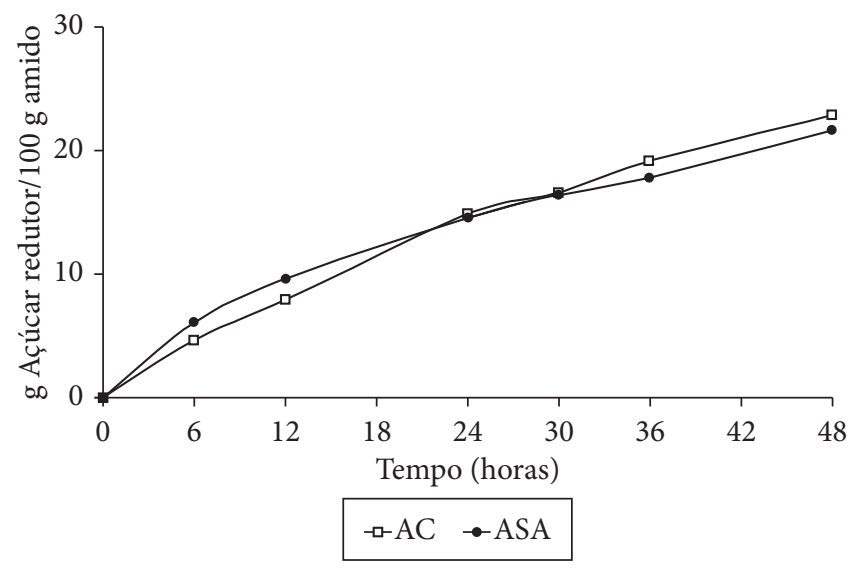

Figura 6. Quantidade de açúcar redutor produzida durante a hidrólise enzimática dos amidos de mandioquinha-salsa.

mais acentuada nas 12 primeiras horas de incubação, seguida por uma diminuição da taxa de hidrólise nos tempos seguintes. A maior velocidade de hidrólise nas primeiras horas de incubação pode ser decorrente da rápida ação inicial da enzima $\alpha$-amilase nas zonas amorfas dos grânulos, produzindo maltose e maltotriose, enquanto a redução da taxa de hidrólise nas horas seguintes, tendendo à estabilização, seria função da ação das enzimas sobre os oligossacarídeos de menor peso molecular para produzir glicose e maltose como produtos finais (TESTER; QI; KARKALAS, 2006). As fendas ou orifícios observados, a partir de microscopia eletrônica de varredura (Figura 3), na superfície dos grânulos de amido de maior diâmetro, de ambas as variedades de mandioquinha-salsa, podem ter contribuído para a ação das enzimas sobre estes amidos.

\subsection{Viscosidade intrínseca}

A viscosidade intrínseca é essencialmente uma medida da fricção interna ou resistência ao deslocamento de moléculas poliméricas em solução, que se utilizada adequadamente, pode 
fornecer um excelente critério de tamanho molecular relativo (ISLAM et al., 2001).

As viscosidades intrínsecas (Tabela 2) dos amidos nativos das duas variedades de mandioquinha-salsa não apresentaram diferença significativa. Alguns pesquisadores têm correlacionado diretamente as propriedades reológicas com a distribuição da massa molecular de polímeros (CHAMBERLAIN; RAO, 2000). Desta forma, os resultados obtidos neste trabalho sugeriram que as massas moleculares dos componentes dos amidos eram semelhantes, concordando com os resultados observados na distribuição do tamanho molecular (Figura 4), em que os picos de amilose e amilopectina foram eluídos no mesmo volume.

Comparando com amidos de outras fontes botânicas, os valores de viscosidade intrínseca encontrados para os amidos de mandioquinha-salsa foram próximos aos observados por Franco, Ciacco e Tavares (1988) para o amido de mandioca $(2,30)$ e maiores que o encontrado para o amido de milho $(1,83)$, utilizando a mesma metodologia deste estudo.

\subsection{Propriedades de pasta}

As propriedades de pasta de amidos estão relacionadas a uma série de fatores, incluindo proporção e tipo de cristalinidade, tamanho e estrutura do grânulo de amido (LINDEBOOM; CHANG; TYLER, 2004).

Os perfis viscoamilográficos (Figura 7) dos amidos das duas variedades de mandioquinha-salsa apresentaram curvas típicas para amidos de tuberosas e foram semelhantes quanto ao formato. $\mathrm{O}$ amido da variedade $\mathrm{AC}$ apresentou temperatura de pasta e valores de viscosidade de pico e viscosidade final inferiores aos observados para o amido da variedade ASA.

A ação da amilose na gelatinização do amido é, ao mesmo tempo, diluente e inibidora do inchamento (SINGH et al., 2003). O maior teor de amilose observado para o amido da variedade AC limitou o inchamento dos grânulos. Além disso, este amido também apresentou maior quantidade de grânulos com tamanho menor que $10 \mu \mathrm{m}$, quando comparado com o amido da variedade ASA. A maior quantidade de grânulos pequenos e, conseqüentemente, o menor diâmetro médio dos grânulos de amido desta variedade, também podem ter contribuído para os menores valores de viscosidade encontrados para este amido. Noda et al. (2005) sugeriram que as viscosidades de pico e de

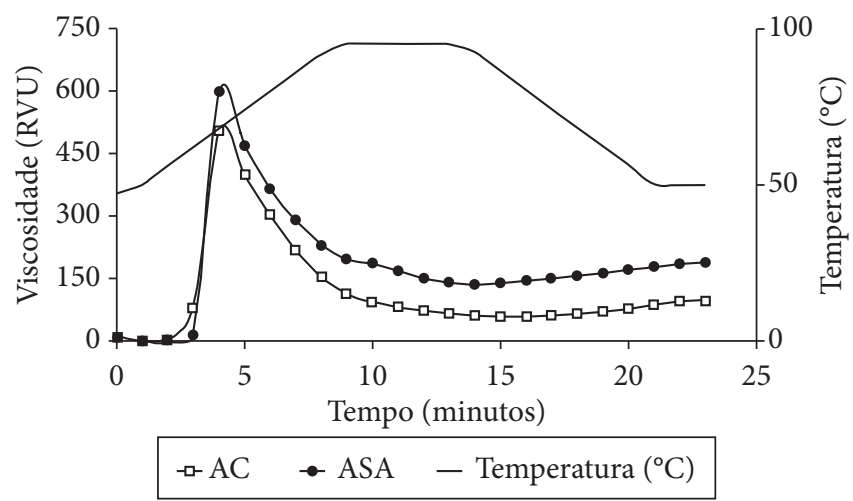

Figura 7. Perfil viscoamilográfico dos amidos de mandioquinha-salsa. quebra são influenciadas pelo tamanho dos grânulos, diminuindo conforme o tamanho dos mesmos diminui.

Ambos os amidos apresentaram valores de quebra consideráveis, indicando fragilidade das pastas frente ao aquecimento e à agitação mecânica.

Os amidos de ambas as variedades apresentaram alto pico de viscosidade, baixa temperatura de pasta e baixa retrogradação, confirmando que o amido de mandioquinha-salsa é de fácil cozimento e de difícil retrogradação e sinérese, como observado por Peroni (2003).

\subsection{Poder de inchamento}

Os perfis de inchamento (Figura 8), obtidos nas temperaturas de 60 a $90{ }^{\circ} \mathrm{C}$, mostraram-se semelhantes quanto ao formato. Foi possível notar um súbito aumento no poder de inchamento de ambos os amidos entre as temperaturas de 60 e $70{ }^{\circ} \mathrm{C}$, enquanto que para temperaturas acima de $70{ }^{\circ} \mathrm{C} \mathrm{o}$ aumento no inchamento foi mais sutil. Este súbito aumento no poder de inchamento (entre 60 e $70^{\circ} \mathrm{C}$ ) sugeriu que os amidos de mandioquinha-salsa apresentaram forças associativas internas frágeis e uniformes, as quais foram rompidas a baixas temperaturas.

O poder de inchamento do amido de mandioquinha-salsa da variedade ASA foi maior do que o apresentado pelo amido da variedade AC para todas as temperaturas testadas, sugerindo que o maior teor de amilose encontrado para este amido limitou o inchamento dos grânulos, influenciando seu poder de inchamento, da mesma forma que influenciou suas propriedades de pasta. Segundo Lindeboom, Chang e Tyler (2004), o poder de inchamento está mais associado com a estrutura do grânulo e a composição química, particularmente o teor de amilose e lipídios, do que com o tamanho dos grânulos.

\subsection{Propriedades térmicas}

As temperaturas de gelatinização, determinadas por DSC, foram menores para o amido da variedade $\mathrm{AC}$, enquanto não houve diferença significativa entre as entalpias de gelatinização para os amidos de ambas as variedades estudadas (Tabela 3). O maior teor de amilose encontrado para o amido da variedade AC pode ter contribuído para as menores tem-

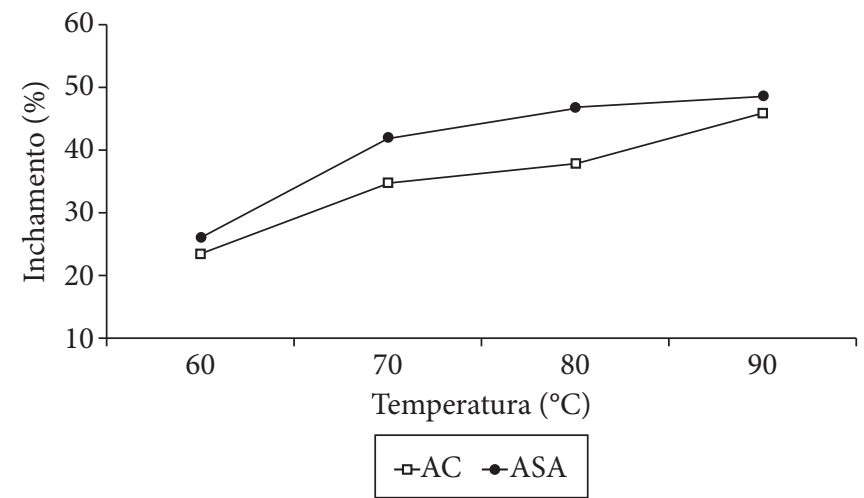

Figura 8. Poder de inchamento dos amidos de mandioquinha-salsa. 
Tabela 3. Propriedades térmicas ${ }^{1}$ dos amidos de mandioquinha-salsa ${ }^{\mathrm{a}}$.

\begin{tabular}{cccccc}
\hline Amido & $\mathrm{T}_{0}^{*}(\mathrm{C})$ & $\mathrm{T}_{\mathrm{p}}^{*}\left({ }^{\circ} \mathrm{C}\right)$ & $\mathrm{T}_{\mathrm{f}}^{*}\left({ }^{\circ} \mathrm{C}\right)$ & $\left(\mathrm{T}_{\mathrm{f}}-\mathrm{T}_{0}\right)$ & $\Delta \mathrm{H}^{*}\left(\mathrm{~J}^{-1}\right)$ \\
\hline AC & $57,21 \pm 0,15^{\mathrm{a}}$ & $60,96 \pm 0,00^{\mathrm{b}}$ & $64,21 \pm 0,04^{\mathrm{b}}$ & 7,00 & $16,1 \pm 1,1^{\mathrm{a}}$ \\
ASA & $57,90 \pm 0,29^{\mathrm{a}}$ & $62,01 \pm 0,07^{\mathrm{a}}$ & $65,29 \pm 0,17^{\mathrm{a}}$ & 7,39 & $15,2 \pm 0,3^{\mathrm{a}}$ \\
\hline
\end{tabular}

${ }^{*} \mathrm{~T}_{0}, \mathrm{~T}_{\mathrm{p}}, \mathrm{T}_{\mathrm{f}}=$ temperatura inicial, de pico e final, respectivamente; $\Delta \mathrm{H}$ : variação de entalpia; ${ }^{1}$ média de três replicatas; ${ }^{\mathrm{a}}$ valores seguidos pela mesma letra na mesma coluna não diferem significativamente pelo teste de Tukey $(\mathrm{p}<0,05)$.

peraturas de gelatinização deste amido, uma vez que maiores proporções de regiões amorfas estariam presentes nos grânulos, diminuindo o ponto de fusão das regiões cristalinas (SINGH et al., 2003). No entanto, como o IC de ambos os amidos não diferiu, não houve diferença significativa entre as entalpias de gelatinização.

As faixas de temperatura de gelatinização apresentadas para os amidos das variedades AC e ASA foram de 7 e $7,39^{\circ} \mathrm{C}$, respectivamente, mostrando serem mais estreitas que as faixas apresentadas por outros amidos como, por exemplo, $20^{\circ} \mathrm{C}$ para amido de batata (GARCIA; WALTER, 1998). Estes resultados sugeriram uma maior perfeição e homogeneidade dos cristais no amido de mandioquinha-salsa. De acordo com Tester (1997), a extensão de perfeições cristalinas é refletida na faixa de temperatura de gelatinização obtida por DSC.

\section{Conclusões}

Os amidos de mandioquinha-salsa das duas variedades estudadas apresentaram diferenças nas suas características estruturais e físico-químicas. Os maiores valores de temperaturas de gelatinização, viscosidade e poder de inchamento, observados para o amido da variedade ASA, podem estar relacionados com a maior proporção de grânulos grandes e menor teor de amilose deste amido.

\section{Agradecimentos}

Os autores agradecem à Fundação de Amparo à Pesquisa do Estado de São Paulo (FAPESP) e à Fundação para o Desenvolvimento da UNESP (FUNDUNESP) pelo apoio financeiro.

\section{Referências bibliográficas}

AACC. Approved Methods of the American Association of Cereal Chemists. 7 ed. St, Paul, Minnesota, 1995. v. 2.

BEMILLER, J. N. Starch modification: challenges and prospects. Starch/Stärke, v. 49, n. 4, p. 127-131, 1997.

BERMUDEZ, J. J. H. Valorización de las amiláceas "no-cereales" cultivadas em los países andinos: estudo de las propiedades fisicoquímicas y funcionales de sus almidones y de la resistencia a diferentes tratamientos estresantes. Bogotá: Trabajo de grado, Facultad de Ingeniería de Alimentos/Universidad de Bogotá, 1977.

BLENNOW, A; ENGELSEN, S. B.; MUNCK, L. Starch molecular structure and phosphorylation investigated by a combined chromatografic and chemometric approach. Carbohydrate Polymers, v. 41, n. 2, p. 163-174, 2000.

BUENO, S. C. S. Produção de mandioquinha-salsa (Arracacia xanthorrhiza) utilizando diferentes tipos de propágulos. Piracicaba, 2004. Dissertação - (Doutorado em Agronomia), ESALQ/USP.
BULÉON, A. et al. Starch granules: structure and biosynthesis - Mini review. International Journal of Biological Macromolecules, v. 23, n. 2, p. 85-112, 1998.

CASALI, V. W. D.; SEDIYAMA, M. A. N. Origem e botânica da mandioquinha-salsa. Informe Agropecuário, v. 19, n. 190, p. 13-14, 1997.

CHAMBERLAIN, E. K.; RAO, M. A. Effect of concentration on rheological properties of acid-hydrolyzed amylopectin solutions. Food Hydrocolloids, v. 14, n. 2, p. 163-171, 2000.

CHEETHAM, N. W. H.; TAO, L. Variation in crystalline type with amylose content in maize starch granules: a X-ray powder diffraction study. Carbohydrate Polymers, v. 36, n. 4, p. 277-284, 1998.

DUBOIS, M. et al. Colorimetric method for determination of sugar and related substances. Analytical Chemistry, v. 28, n. 3, p. 350-354, 1956.

FOX, J. D.; ROBYT, J. F. Miniaturization of three carbohydrate analyses using a microsample plate reader. Analytical Biochemistry, v. 195, n. 1, p. 93-96, 1991.

FRANCO, C. M. L.; CIACCO, C. F. Factors that affect the enzymatic degradation of natural starch granules. Effect of size of the granules. Starch/Stärke, v. 44, n. 11, p. 422-426, 1992.

FRANCO, C. M. L.; CIACCO, C. F.; TAVARES, D. Q. Studies on the susceptibility of granular cassava and corn starches to enzymatic attack. Part 2. Study of the granular structure of starch. Starch/ Stärke, v. 40, n. 1, p. 29-32, 1988.

FRANCO, C. M. L. et al. Propriedades do Amido. In: Culturas de Tuberosas Amiláceas Latino Americanas, Propriedades Gerais do Amido. Campinas: Fundação Cargill, 2001. v. 1.

FRANCO, C. M. L. et al. Structural and functional characteristics of selected soft wheat starches. Cereal Chemistry, v. 79, n. 2, p. 243-248, 2002.

FRENCH, D. Organization of starch granules. In: WHISTLER, R. L.; BEMILLER, J. N.; PASCHAL, E. F. Starch: Chemistry and Technology. 2 ed. London: Academic Press, 1984. p. 183-247.

GARCIA, A. M.; WALTER, W. M. Physicochemical characterization of starch from peruvian sweet potato selections. Starch/Stärke, v. 50, n. 8, p. 331-337, 1998.

GONZÁLES, G.; CARRASCO, R. R. Extracción y caracterización del almidon de peruvian carrot (Arracacia Xanthorriza Bancroft) y su resistencia a tratamientos tecnológicos. In: SIMPÓSIO LATINO AMERICANO DE RAICES Y TUBERCULOS, 2, 2001, Lima. Anais... Lima: FS, p. 1 -12, 2001.

HAYAKAWA, K. et al. Quality characteristics of hexaploid wheat (Triticum aestivum L.): properties of starch gelatinization and retrogradation. Cereal Chemistry, v. 74, n. 5, p. 576-580, 1997.

HOOVER, R. Composition, molecular structure, and physicochemical properties of tuber and root starches: A Review. Carbohydrate Polymers, v. 45, n. 3, p. 253-267, 2001.

ISLAM, M. N. et al. Effect of temperature and starch concentration on the intrinsic viscosity and critical concentration of sago starch (Metroxylon sagu). Starch/Stärke, v. 53, n. 2, p. 90-94, 2001. 
ISO - International Organization for Standardization. Norme internationale: Riz-détermination de la teneur em amylose. S. I., 1987. 5 p. (ISO 66470).

JULIANO, B. O. A simplified assay for milled-rice amylose. Cereal Science Today, v. 16, n. 10, p. 334-340, 1971.

KASEMSUWAN, T.; JANE, J. Location of amylose in normal starch granules. II. Location of phosphodiester cross-linking revelead by phosphorous-31 nuclear magnetic resonance. Cereal Chemistry, v. 71, n. 3, p. 282-287, 1994.

LANSKY, S.; KOOI, M.; SCHOCH, T. J. Properties of the fractions and linear sub fraction from various starches. Journal of the American Chemical Society, v. 71, n. 12, p. 1066-4075, 1949.

LEACH, H. W. Determination of intrinsic viscosity of starches. Cereal Chemistry, v. 40, n. 6, p. 593-600, 1963.

LIM, S. T.; KASEMSUWAN, T.; JANE, J. L. Characterization of phosphorous in starch by p-31 nuclear magnetic-resonance spectroscopy. Cereal Chemistry, v. 71, n. 5, p. 468-472, 1994.

LINDEBOOM, N.; CHANG, P. R.; TYLER, R. T. Analytical, biochemical and physicochemical aspects of starch granule size, with emphasis on small granule starches: a review. Starch/Stärke, v. 56, n. 3-4, p. 89-99, 2004.

LINEBACK, D. R. The starch granule: Organization and properties. Bakers Digest, v. 58, n. 2, p. 16-21, 1984.

MIZUKAMI, H.; TAKEDA, Y.; HIZUKIRI, S. The structure of the hotwater soluble components in the starch granules of new Japanese rice cultivars. Carbohydrate Polymers, v. 38, n. 4, p. 329-335, 1999.

NODA, T. et al. Physicochemical properties and amylopectin structure of large, small and extremely small potato starch granules. Carbohydrate Polymers, v. 60, n. 2, p. 245-251, 2005.

PARKER, R.; RING, S. G. Aspects of the physical chemistry of starch. Journal of Cereal Science, v. 34, n. 1, p. 1-17, 2001.

PEREIRA, A. S. O valor nutritivo da mandioquinha-salsa. In: ENCONTRO NACIONAL SOBRE MANDIOQUINHA-SALSA, 5, 1995, Venda Nova do Imigrante. Palestra e Trabalhos Técnicos... Venda Nova do Imigrante: SOB, 1995. p. 14-16.

PERONI, F. H. G. Características estruturais e físico-químicas de amidos obtidos de diferentes fontes botânicas. São José do Rio Preto, 2003. Dissertação - (Mestrado em Ciência e Tecnologia de Alimentos), IBILCE - UNESP.

PERONI, F. H. G.; ROCHA, T. S.; FRANCO, C. M. L. Some structural and physicochemical characteristics of tuber and root starches.
Food Science and Technology International, v. 12, n. 6, p. 505-513, 2006.

$\mathrm{SCHOCH}, \mathrm{T}$. J. Swelling power and solubility of granular starches. In: WHISTLER, R. L. Methods in Carbohydrate Chemistry; Starch. New York: Academic Press, 1964. p. 106-109. v. 4.

SINGH, N. et al. Morphological, Thermal and Reological Properties of Starches from Different Botanical Sources. Food Chemistry, v. 81, n. 2, p. 219-231, 2003.

SMITH, A. R.; CARUSO, T. E. Determination of phosphorous content. In: WHISTLER, R. L. Methods in Carbohydrate Chemistry; Starch. New York: Academic Press, 1964. p. 43-47. v. 4.

SOMOGYI, M. New reagent for the determination of sugars. The Journal of Biological Chemistry, v. 160, n. 1, p. 61-68, 1945.

SONG, Y.; JANE, J. Characterization of barley starches of waxy, normal and high amylose varieties. Carbohydrate Research, v. 41, n. 4, p. 365-377, 2000.

TANG, H.; WATANABE, K.; MITSUNAGA, T. Structure and functionality of large, medium and small granule starches in normal and waxy barley endosperms. Carbohydrate Polymers, v. 49, n. 2, p. 217-224, 2002.

TESTER, R. F. Properties of damaged starch granules: composition and swelling properties of maize, rice, pea and potato starch fractions in water at various temperatures. Food Hydrocolloids, v. 11, n. 3, p. 293-301, 1997.

TESTER, R. F.; MORRISON, W. R. Swelling and gelatinization of starches 1. Effects of amylopectins, amyoses and lipids. Cereal Chemistry, v. 67, n. 6, p. 551-557, 1990.

TESTER, R. F.; QI, X.; KARKALAS, J. Hydrolysis of native starches with amylases. Animal Feed Science and Technology, v. 130, n. 1-2, p. 39-54, 2006.

VIEIRA, F. C. Efeito do tratamento com calor e baixa umidade sobre características físicas e funcionais dos amidos de mandioquinhasalsa (Arracacia xanthorriza), de batata-doce (Ipomoea batatas) e de gengibre (Zingiber officinale). Piracicaba, 2004. Dissertação - (Mestrado Ciências), ESALQ/USP.

WANG, Y. J. et al. Amylopectin and intermediate materials in starches from mutant genotypes of the inbred line. Cereal Chemistry, v. 70, n. 5, p. 521-525, 1993.

WANG, W. J.; POWELL, A. D.; OATES, C. G. Pattern of enzyme hydrolysis in raw sago starch: effects of processing history. Carbohydrate Polymers, v. 26, n. 1, p. 91-97, 1995. 